\title{
Como os acontecimentos \\ se tornam notícia: \\ Uma revisão do conceito de noticiabilidade \\ a partir das contribuições discursivas
}

\author{
Marcos Paulo da Silva*
}

Resumo: A definição conceitual de noticiabilidade não elimina o campo jornalístico de uma das principais indagações sobre o assunto: como ocorre a definição de tais critérios ou, em outros termos, como os acontecimentos, de fato, tornam-se notícia? Neste cenário, a delimitação do conceito de noticiabilidade carece de complementação a partir do aprimoramento teórico dos critérios que antecedem e caracterizam a seleção de notícias. O objetivo do artigo é revisitar o debate conceitual a respeito da noticiabilidade com a intenção de compreender seus processos no interior de um quadro de referência próprio das teorias discursivas a partir das contribuições de Patrick Charaudeau.

Palavras-chave: Jornalismo; noticiabilidade; discurso social.

How does the events become news:

A review of the concept

\section{of newsworthiness with discursive contributions}

\begin{abstract}
The conceptual definition of newsworthiness does not eliminate one of the main questions about the subjetc in journalism investigation: how are such criteria defined or, in other words, how do the events, actually, become news? Delimiting the newsworthiness concept needs the complementary theoretical achievements over the criteria that lays behind and before the selection of news. The objective of this article is to revisit the conceptual debate about the newsworthiness, intending to understand processes within the theoretical frame offered by discursive analysis, particularly as understanded by Patrick Charadeau.
\end{abstract}

Keywords: Journalismo; newsworthness; social discourse.
Artigo recebido em: 3 de fevereiro de 2010 Aprovado em:

5 de maio de 2010

* Mestre em Comunicação pela Universidade Estadual Paulista (UNESP) e Doutorando em Comunicação Social pela Universidade Metodista de São Paulo (UMESP). Bolsista do Conselho Nacional de Desenvolvimento Científico e Tecnológico (CNPq).

silva_mp@uol.com.br 


\section{Para situar o debate}

$\mathrm{P}$ or que as notícias são como são? O questionamento elaborado em 1988 por Michael Schudson e retomado anos depois em obras de autores como Nelson Traquina (2008) e Jorge Pedro Sousa (2002) é sintomático de um debate que permeia o jornalismo desde sua gênese e percorre discussões teóricas ainda nos dias atuais.

A ideia de existência de critérios de noticiabilidade remete, ao menos, a Johan Galtung e Mari Holmboe Ruge (1999) ${ }^{1}$, pioneiros em apresentar uma lista sistematizada de valores-notícia. Ao desenvolverem um estudo sobre a cobertura de três crises internacionais - Congo, Cuba e Chipre - em jornais estrangeiros, os pesquisadores dinamarqueses são os primeiros teóricos a reconhecer a existência de critérios de noticiabilidade como critérios suscetíveis de permitir a atribuição de valor noticioso a fatos e acontecimentos de forma a se sobrepor à subjetividade jornalística. Os autores partem do entendimento de que a comunicação noticiosa estrutura-se como uma cadeia, sendo esta iniciada a partir dos acontecimentos caóticos do mundo e encerrada na imagem pessoal produzida pelo receptor. Assim, focam-se na etapa inicial do processo: a percepção, a seleção e a construção de uma imagem dos acontecimentos pelos meios de comunicação.

O estudo de Galtung e Ruge (1999) consiste na primeira experiência teórica de elaboração de uma tipologia para os critérios de noticiabilidade no jornalismo. Decorre daí o fato de a pesquisa ter se tornado referência nos estudos comunicacionais que adotam jornais como recorte empírico. Contudo, o modo como os autores apresentam sua perspectiva, amparados em hipóteses que seguem relações matemáticas (o que revela uma ancoragem no modelo positivista da ciência), enrijece as categorias de valores-notícia e coloca o estudo em uma posição passível de revisões críticas a partir de abordagens guiadas pela perspectiva culturalista.

Muito antes de Galtung e Ruge, que elaboram seus estudos sobre jornalismo na década de 1960, esboços da concepção de noticiabilidade já eram indicados em trabalhos seminais, como é o caso da famosa tese de Tobias Peucer², defendida em 1690, na Alemanha. Apesar de aparentemente não ter pretendido uma teoria para o jornalismo, Peucer acabou por delinear importantes conceitos retomados séculos depois em pesquisas sobre jornalismo (SOUSA, 2004). A concepção de notícia trabalhada pelo autor alemão é essencialmente descritiva, embora universal e atual, e dilui-se em diferentes partes do trabalho (SOUSA, 2004, p. 36-37). Em resumo, segundo Tobias Peucer, as notícias constituem relatos expositivos e escritos; sobre singularidades; selecionados entre vários relatos possíveis segundo a sua importância; condicionados por fatores como o tempo; que se orientam para os acontecimentos; e que são novos, isto é,

1 O estudo original data de 1965: GALTUNG, J. e RUGE, M. The structure of foreign news. Journal of Internacional Peace Research, n. 1, 1965. O texto foi traduzido e publicado em língua portuguesa, em 1999, com o título "A estrutura do noticiário estrangeiro - A apresentação das crises do Congo, Cuba e Chipre em jornais estrangeiros" como capítulo do livro organizado por Nelson Traquina: TRAQUINA, Nelson (org). Jornalismo: questões, teorias e estórias. 2. Ed. Lisboa: Veja, 1999.

2 O estudo "De Relationibus Novellis", de Tobias Peucer, tem suas principais partes traduzidas em língua portuguesa no texto "Tobias Peucer: o progenitor da Teoria do Jornalismo", de Jorge Pedro Sousa, publicado no Brasil pela Universidade Federal de Santa Catarina. (SOUSA, 2004). 
oferecem novidades, o que satisfaz a curiosidade humana (SOUSA, 2004, p. 37). Tais peculiaridades dialogam com questões contemporâneas relativas ao estudo do jornalismo, tais como os constrangimentos sofridos no processo de seleção das notícias, a atividade de gatekeeping, o foco nos acontecimentos (em detrimento às problemáticas) e, sobretudo, a existência de critérios de noticiabilidade.

Mesmo construído historicamente a partir da contribuição de estudos que se tornaram referenciais, como a tese de Peucer e a tipologia de Galtung e Ruge, todavia, o conceito de noticiabilidade ainda consiste em tema de recorrentes controvérsias entre os próprios profissionais jornalistas, conforme alerta Traquina (2008): "Diversos estudos sobre o jornalismo demonstram que os jornalistas têm uma enorme dificuldade em explicar o que é notícia, de explicitar quais são seus critérios de noticiabilidade, para além de respostas vagas do tipo 'o que é importante' e/ou 'o que interessa ao público'” (TRAQUI$\mathrm{NA}, 2008$, p.62). Na contramão das controvérsias, o próprio autor português oferece uma definição lúcida do conceito:

Podemos definir o conceito de noticiabilidade como o conjunto de critérios e operações que fornecem a aptidão de merecer um tratamento jornalístico; isto é, possuir valor como notícia. Assim, os critérios de noticiabilidade são o conjunto de valores-notícia que determinam se um acontecimento, ou assunto, é susceptível de se tornar notícia, isto é, de ser julgado como merecedor de ser transformado em matéria noticiável e, por isso, possuindo 'valor-notícia'. (TRAQUINA, 2008, p. 63).

A definição conceitual de noticiabilidade, entretanto, não elimina o campo jornalístico de uma das principais indagações sobre o assunto: como ocorre a definição de tais critérios ou, em outros termos, como os acontecimentos, de fato, tornam-se notícia? Neste cenário, a delimitação do conceito de noticiabilidade carece de complementação a partir do aprimoramento teórico dos critérios que antecedem e caracterizam a seleção de notícias. Em última instância, não basta questionar o porquê de as notícias se caracterizarem como tais, mas - ainda além - quais os motivos que levam determinados assuntos a receberem a valoração de notícias em detrimentos de outros.

Este artigo localiza-se em torno de tais questões. O objetivo é revisitar o debate conceitual a respeito da noticiabilidade com a intenção de compreender seus processos no interior de um quadro de referência próprio das teorias discursivas a partir das contribuições de Patrick Charaudeau (2003).

\section{Noticiabilidade: as contribuições da teoria discursiva de Charaudeau}

Entre as principais contribuições levadas ao campo das ciências sociais pelo teórico francês Patrick Charaudeau figura-se uma visão peculiar dos proces- 
sos de trocas simbólicas embutidos nos discursos sociais. É neste sentido que Charaudeau localiza dois de seus principais compromissos teóricos: as articulações entre os planos situacional e linguístico e entre os planos macro e microssocial.

Neste cenário, o teórico francês procura entender cada discurso social como uma "articulação íntima, bidirecional, não determinista, entre os planos situacional e linguístico" (NOGUEIRA, 2004, p. 3); compromisso que se operacionaliza em torno da concepção de "contrato de comunicação".

Para Charaudeau, todo ato de linguagem realiza-se dentro de um tipo específico de relação contratual, implicitamente reconhecido pelos sujeitos, e que define, por um lado, aspectos ligados ao plano situacional - qual a identidade dos parceiros, seus objetivos, o assunto de que falam, em que circunstâncias materiais - e, por outro, aspectos relativos ao plano comunicacional e discursivo - quais as maneiras de dizer ou quais as estratégias discursivas pertinentes. (NOGUEIRA, 2004, p. 3).

Ainda no interior da concepção de contrato, Charaudeau propõe uma compreensão diferenciada para os diálogos estabelecidos nos planos macro e microssocial - percepção que foge das interpretações mecanicistas ou deterministas dadas a esses planos:

Os atributos decorrentes das posições macroestruturais ocupadas pelos sujeitos só tornam-se relevantes em articulação com as circunstâncias microssociais em que eles atuam. Charaudeau vai, no entanto, ainda mais longe. Não basta a existência de uma adequação entre a localização macroestrutural do sujeito (com os atributos daí decorrentes) e as circunstâncias e objetivos de sua atuação. É necessário que esses atributos sejam reconhecidos pelos sujeitos destinatários para que eles se tornem operantes, e esse reconhecimento ocorre, justamente, dentro do encontro linguageiro, através da interação e avaliação mútua dos interlocutores. (NOGUEIRA, 2004, p. 4).

Desta maneira, elucidados - ainda que sucintamente - os referidos compromissos teóricos de Patrick Charaudeau, permite-se a introdução das reflexões estabelecidas pelo que o autor em torno do "discurso da informação", ou seja, do tipo específico de discurso que rege a mídia. O objetivo é tirar deste debate novas reflexões para o entendimento da dinâmica de funcionamento dos valores-notícia, tema do presente trabalho. 


\section{As engrenagens da máquina midiática}

Patrick Charaudeau (2003, p.11) defende os meios de comunicação como suportes institucionais que se apoderam de diferentes conceitos para integrálos em suas diferentes lógicas: econômica, tecnológica e simbólica. Porém, segundo o autor, uma lógica específica se sobressai no âmbito do discurso da informação: a simbólica.

Sem nenhuma dúvida, a lógica econômica e a lógica tecnológica são elementos inescapáveis, mas aqui nos interessa a lógica simbólica, que trata do modo como indivíduos regulam os intercâmbios sociais e constroem as representações que dão aos valores que são subjacentes em suas práticas, quando criam e manipulam signos. Assim produzem sentido e, finalmente, não há o menor dos paradoxos no fato de que seja esta lógica que rege as demais. (CHARAUDEAU, 2003, p. 12). [tradução do autor].

$\mathrm{Na}$ contramão das interpretações que observam na mídia apenas motivações econômicas ou determinações tecnológicas, Charaudeau (2003) argumenta que os indivíduos envolvidos na elaboração dos discursos sociais (entre esses discursos está o midiático) agem a partir da construção de sistemas de valores. Assim, caem por terra três premissas vistas por Charaudeau (2003, p.13-15) como mal-entendidos teóricos, a saber: os meios de comunicação são instâncias de poder; os meios de comunicação são manipuladores da sociedade; e os meios de comunicação são reprodutores transparentes da realidade social. Por outro lado, na concepção do autor francês, os veículos de mídia devem ser vistos como construtores particulares do espaço público.

Os meios de comunicação, se são um espelho, somente são um espelho deformante ou, ainda melhor, são vários espelhos ao mesmo tempo daqueles que, nas férias, e apesar da deformação, dão testemunho, cada um a sua maneira, de uma parcela amplificada, simplificada e estereotipada do mundo. (CHARAUDEAU, 2003, p.15). [tradução do autor].

Segundo Charaudeau (2003, p. 22-23), seguindo em sua perspectiva conceitual, a articulação entre as três lógicas - econômica, tecnológica e simbólica - no discurso da informação (chamada pelo autor de "máquina midiática") ocorre em três lugares de pertinência: nas condições de produção (instância de enunciação), na construção do discurso propriamente dito e nas condições de interpretação (instância de recepção), conforme ilustra o modelo gráfico (figura 1).

Por se tratar de um estudo sobre valores-notícia, o presente trabalho focase nos dois primeiros lugares de pertinência da máquina midiática. Aborda-se, desta forma, os processos de seleção dos acontecimentos (lugar das condições 
de produção) e de construção noticiosa (lugar de construção do discurso).

Figura 1: Os lugares de pertinência da "máquina midiática"

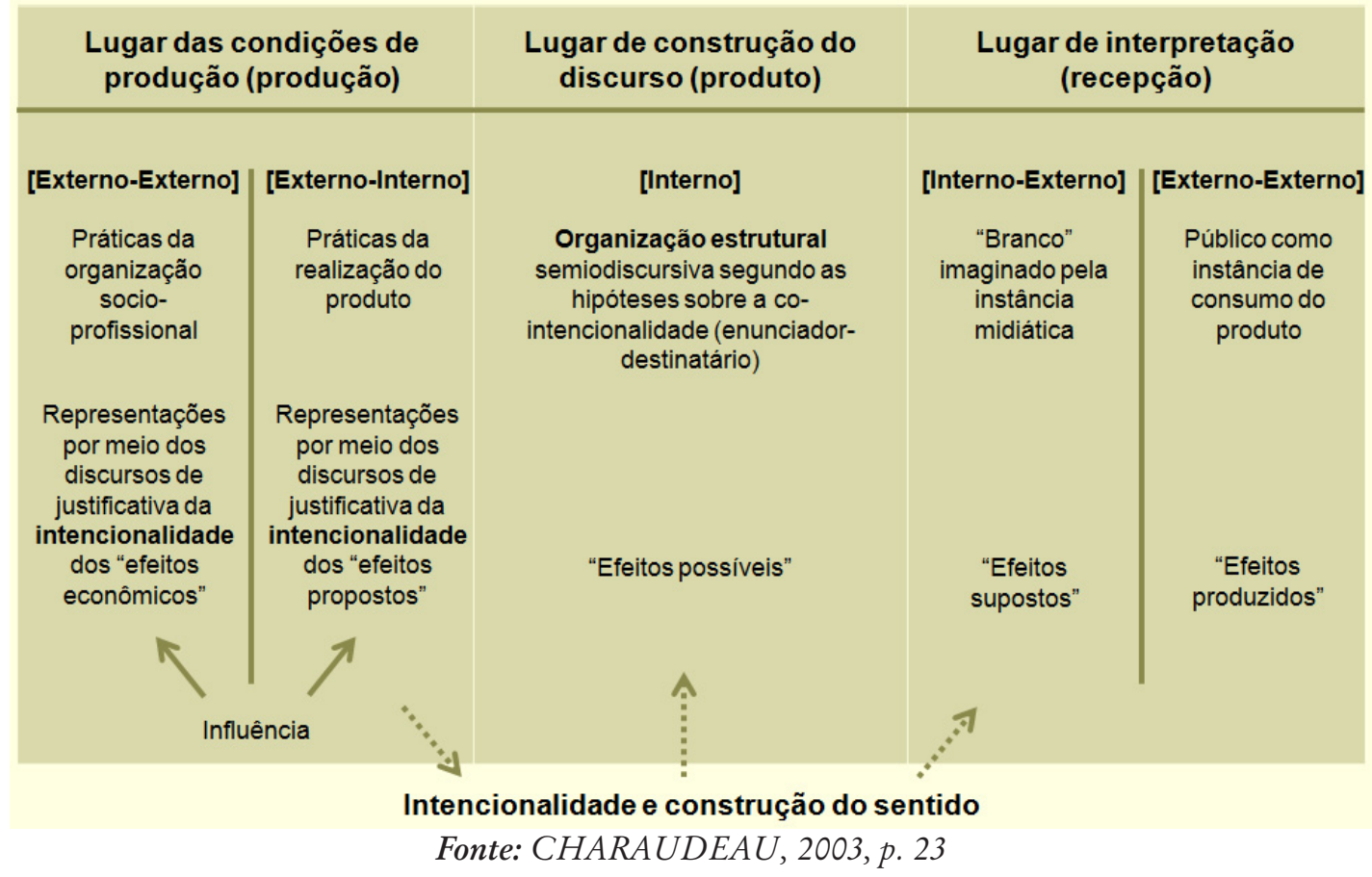

Conforme é observável no modelo gráfico, o lugar das condições de produção das notícias (instância de enunciação) se estrutura em dois espaços distintos: o externo-externo, que compreende as condições socioeconômicas envolvidas no processo comunicacional; e o externo-interno, responsável por abarcar as condições semiológicas da produção. Assim, ao entender a notícia como produto de uma determinada empresa cuja organização está regida por práticas institucionalizadas (que se relacionam com os estatutos e as funções dos atores nela envolvidos), o externo-externo configura-se como uma problemática de ordem socioeconômica. Este espaço (externo-externo), emaranhado nas práticas profissionais da organização, dialoga - num processo de influências mútuas - com o espaço externo-interno, responsável pela realização propriamente dita (escolhas temáticas, entre outras) do produto midiático. Em outros termos, pode-se dizer que as variáveis socioeconômicas que caracterizam o espaço externo-externo influenciam as escolhas discursivas dos jornalistas na construção da notícia (externo-interno), e vice-versa. Ademais, entende-se que a instância de enunciação da máquina midiática trabalha com "efeitos propostos", já que o destinatário não é conhecido e, numa perspectiva ideal, só pode ser considerado como um "vazio" a ser "preenchido" pelas significações propostas.

Por sua vez, o lugar de construção do discurso se configura segundo uma organização semiodiscursiva, ou seja, a partir da disposição de formas que pertencem, predominantemente, ao sistema verbal e a outros sistemas semiológicos, como o icônico, o gráfico e o gestual. Diferentemente do lugar das condições de produção, baseado essencialmente em questões de intencionalidade (já que o destinatário só pode ser imaginado idealmente), o lugar da construção do discurso estrutura-se numa relação de co-intencionalidade, uma vez que se reconhece o destinatário num processo de intercâmbio comunicativo (resultando em "efeitos possíveis"): 
Por uma parte, a instância de enunciação somente pode imaginar o receptor de uma maneira ideal, quer dizer, construílo por hipóteses em um destinatário supostamente adequado às suas intenções, sem prejulgar, portanto, sobre sua atividade interpretante real, e como, por outra parte, esta instância de enunciação não pode pretender dominar a totalidade de sua própria intencionalidade, dito que, como ser coletivo, leva consigo vários campos de significação dos quais não necessariamente possui consciência, nos vemos obrigados a concluir que o texto produzido é portador de uma co-intencionalidade que se estabelece entre o enunciador e o destinatário (seres de fala) e não entre o produtor e o receptor (seres atuantes). (CHARAUDEAU, 2003, p. 25). [tradução do autor].

Conclui-se, neste contexto, que texto jornalístico nasce carregado de efeitos possíveis, ao passo que somente uma parte desses efeitos corresponde às intenções conscientes do enunciador; outra parte, não necessariamente a mesma, será reconstruída pelo receptor (idem, p. 26).

Portanto, nas circunstâncias de análise de produtos noticiosos (entendidos como atos comunicativos), convém distinguir os "efeitos propostos" (localizados no lugar das condições de produção) dos "efeitos possíveis" (localizados no lugar de construção do discurso) e dos "efeitos produzidos" (localizados no lugar de interpretação) (ibidem, p. 45). Assim, as seleções de fatos noticiáveis e as subsequentes escolhas linguísticas realizadas na construção das notícias devem ocorrer sempre em função de receptores pré-idealizados e dos efeitos pretendidos. Tratam-se, portanto, de processos de seleção, seja no âmbito do falar, do comunicar ou do informar:

É evidente que falar, comunicar, informar, tudo é seleção. Não somente seleção de conteúdos para transmitir e de formas adequadas para expressar-se de acordo com as normas corretas e de clareza, mas também seleção de efeitos de sentido para influir sobre o outro, quer dizer, no final das contas, seleção de estratégias discursivas. (ibidem, p. 47). [tradução do autor].

Intrínsecos em tais escolhas residem os processos de construção de sentido do discurso informativo - são dois, chamados de "transformação" e "transação” (ibidem, p.50-21). Entende-se que o ato de informar se inscreve em um processo típico de transformação, pois é responsável por descrever, contar e explicar algo, ou, em outras palavras, por transformar um "mundo por significar” em um “mundo significado”. Tal processo de transformação é regido, no entendimento da teoria discursiva de Patrick Charaudeau (2003), pelo processo de transação. Assim, o ato de comunicar inscreve-se também em uma dinâmica de transação, pois, para que seja válido, os interlocutores devem estar em condições de reconhecer o mesmo marco de intencionalidade. Os processos podem ser visualizados segundo o modelo gráfico: 
Figura 2: Dinâmica dos processos de "transformação" e "transação"

\begin{tabular}{|llll|}
\hline $\begin{array}{l}\text { Mundo por } \\
\text { descrever e } \\
\text { comentar }\end{array}$ & $\begin{array}{l}\text { Instância de } \\
\text { produção da } \\
\text { informação }\end{array}$ & $\begin{array}{c}\text { Mundo } \\
\text { descrito e } \\
\text { comentado }\end{array}$ & $\begin{array}{c}\text { Instância de } \\
\text { recepção- } \\
\text { interpretação }\end{array}$ \\
\hline
\end{tabular}

Fonte: CHARAUDEAU, 2003, p. 52

Assim, todo discurso, antes de manifestar o mundo, manifesta uma relação. A mesma lógica vale para o discurso informativo. O sujeito informante, "preso" nas redes do processo de transação, somente pode construir sua informação (processo de transformação) em função de dados específicos da situação de intercâmbio (CHARAUDEAU, 2003, p.52).

No contexto do contrato de comunicação, marcado em sua dinâmica pela influência dos dados externos - ou seja, pelas práticas sociais que caracterizam os condicionamentos situacionais - e, ao mesmo tempo, pelos dados internos - localizados no interior propriamente dito das escolhas discursivas (condicionamentos discursivos) - os processos de transformação e transação

Figura 3: Processos de "transformação" e "transação" no âmbito do contrato de comunicação de Patrick Charendeau (2008)

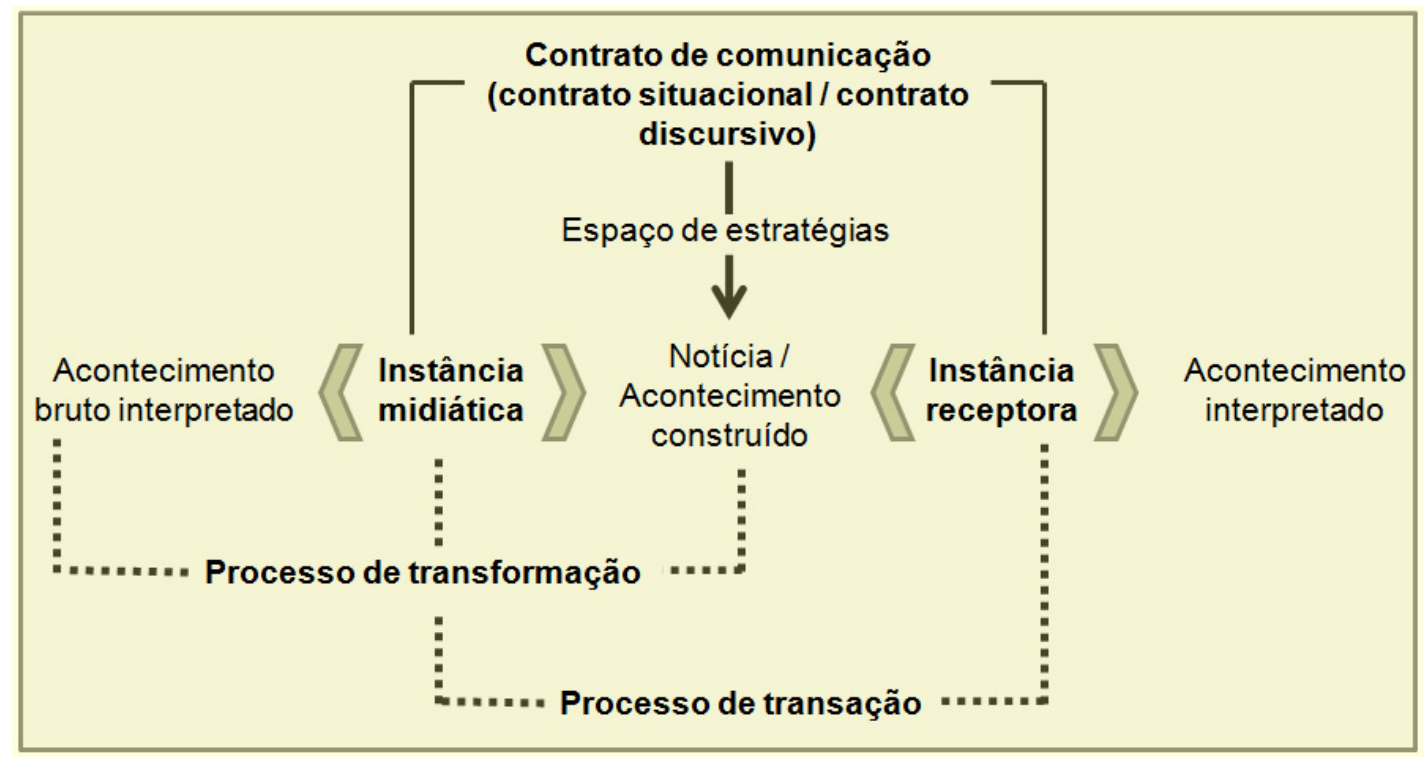

Fonte: CHARAUDEAU, 2003, p. 83

podem ser ilustrados da seguinte maneira:

Por conseguinte, abordar o modo como aparecem e circulam os discursos sociais (entre eles o discurso midiático) consiste, primeiramente, em tentar descrever os condicionamentos situacionais e discursivos dos contratos de comunicação em que se inserem e adquirem sentido; e, em um segundo momento, os tipos de estratégias que aparecem de maneira recorrente no interior deste campo contratual (idem, p. 82).

\section{4. $\mathrm{O}$ acontecimento midiático}

Apresentados conceitualmente os modos de funcionamento da chamada máquina midiática e do contrato de comunicação na perspectiva de Patrick Charaudeau (2003), parte-se para o entendimento, no âmbito da teoria dis- 
cursiva, da dinâmica de seleção e construção dos acontecimentos midiáticos - reflexão que permite diálogo com as abordagens conceituais sobre critérios de noticiabilidade no jornalismo.

Segundo Charaudeau (2003, p. 79), um dos principais dados externos do contrato de comunicação consiste no "tema", ou, em seus termos, naquele dado que possibilita a fragmentação semântica do mundo (tematização). Por sua vez, a noção de tema liga-se intrinsecamente ao conceito de acontecimento, ou seja, os acontecimentos do mundo, conforme define o autor francês, somente adquirem sentido por meio de uma estruturação que lhes dão os atos de linguagem e de tematização (idem, p. 117).

Para Charaudeau (p. 118), o acontecimento se encontra no âmbito do "mundo a comentar" (processo de transformação) e, portanto, nunca pode ser transmitido em estado bruto (já que depende de uma determinada significação). Assim, compreende-se que no mundo surgem acontecimentos a todo momento e numa ordem complexa, configurando-se em "estados" (conjunto de qualidades ou características). Tais estados são constantemente modificados, fenômenos que somente adquirem existências significativas por meio de um processo de percepção-captação-sistematização-estruturação trazido à tona por um sujeito linguístico - pois, ao serem relatados os acontecimentos corporificam um significado.

O trabalho de ordenamento de sentido dos acontecimentos (passagem do "mundo a comentar" ao "mundo comentado") rege-se, segundo Charaudeau (ibidem, p. 122), por uma dupla faculdade: a percepção dos fenômenos estruturados no tempo e no espaço; e a estruturação temática do mundo ao ser "comentado" por meio da linguagem. Nesta perspectiva, um acontecimento nasce, vive e morre no interior de um processo dialético que depende do sujeito que interpreta o mundo (ibidem, $\mathrm{p}$. 122). Portanto, em um estudo sobre a construção do sentido (bem como em um estudo sobre noticiabilidade), não interessa o acontecimento em si (fenomênico), mas o processo de construção do acontecimento.

Algumas considerações de Patrick Charaudeau sobre o processo de seleção dos acontecimentos midiáticos são relevantes para o entendimento da dinâmica dos valores-notícia no jornalismo. Para o autor, a construção de um acontecimento noticioso depende, quase necessariamente, de que ele seja, no mundo fenomênico, um acontecimento insólito (dinâmica que ressalta o "inesperado" como valor-notícia). Assim ocorre, pois os meios de comunicação buscam tratar os acontecimentos em seus aspectos acidentais em oposição à regularidade.

Patrick Charaudeau (ibidem, p. 125) ainda refina seu raciocínio e argumenta que a finalidade da informação midiática é dar conta do que ocorre no espaço público. $\mathrm{Na}$ visão do autor, o espaço público não possui significação por si mesmo, mas depende dos vários discursos sociais (entre eles o discurso midiático) que o fazem inteligível. Os discursos que permitem a inteligibilidade do mundo, por sua vez, dependem dos grupos sociais nos quais estão inseridos e dos sistemas de valores por eles produzidos (CHARAUDEAU, 2003, p. 165). 
Neste debate, insere-se a problemática do acontecimento noticioso. Segundo Charaudeau (2003, p. 174), se por um lado aceita-se como premissa o fato de que a seleção efetuada pelos meios de comunicação tende a impor uma determinada divisão do espaço público e uma determinada caracterização do acontecimento, por outro, é necessário delimitar quais são os critérios que regem tal seleção. $\mathrm{O}$ autor propõe uma classificação a partir de dois tipos de critérios: externos e internos.

Entende-se por critérios externos aqueles que se referem ao modo de aparição do acontecimento e que podem ser classificados de três formas:

- O acontecimento como fatalidade: aquele que não pode ser previsto por sistemas de expectativas da vida social;

- O acontecimento programado: marcado pela existência de um calendário que dispõe de organização e desenvolvimento da vida social;

- O acontecimento suscitado: preparado e provocado por algum setor institucional com fins estratégicos de pressão sobre a opinião pública. (CHARAUDEAU, 2003, p. 174-175).

Por critérios internos entendem-se aqueles marcados pelas opções realizadas na instância midiática. Tais opções dependem do modo como os meios representam a inteligibilidade social e da maneira como criam hierarquias para os acontecimentos. A relação entre os critérios externos e internos não é determinista (relação de causa e efeito), mas a partir de um jogo constante de tensões. Em decorrência do processo de hierarquização dos acontecimentos estabelecido pelos critérios internos e externos de seleção, estabelece-se a divisão midiática do mundo (idem, p. 177).

$\mathrm{Na}$ perspectiva de Patrick Charaudeau, um acontecimento midiático é selecionado e construído em função de seus potenciais de "atualidade" (estatuto que caracteriza a distância temporal entre o acontecimento fenomênico e o momento de sua informação midiática); "sociabilidade" (diz respeito aos aspectos que afetam os cidadãos no espaço público); e "imprevisibilidade" (capacidade de captar a atenção, o interesse e o afeto do destinatário idealizado pelo enunciador; o acontecimento eleito deve perturbar a tranquilidade do sistema de expectativas do sujeito consumidor de informações).

Conforme exposto, nota-se que a concepção de noticiabilidade de Patrick Charaudeau (2003) está intimamente relacionada à noção de espaço público. Tal relação, por sua vez, está sujeita a um duplo jogo de influências - centrípedo e centrífugo - no interior de um grupo social.

O espaço público não é algo único, não é um fato nem um ponto de partida. Resulta da conjunção das práticas sociais e das representações. As primeiras constituem o motor das segundas, e estas dão àquelas sua razão de ser ao atribuí-las valores que tendem a reafirmá-las ou modificá-las. Esta interação dialética constrói um espaço público plural e móvel. (CHARAUDEAU, 2003, p. 132). [tradução do autor].

Segue-se a esta definição o raciocínio de que os meios de comunica- 
ção não se apoderam do espaço público, mas participam constantemente de sua constituição e transformação. Neste raciocínio, o "tema" (dado que possibilita a fragmentação semântica do mundo) - entendido conceitualmente como componente do contrato de comunicação - se inscreve no processo de construção do acontecimento midiático. Atua, assim, na divisão do mundo em universos de discurso, abordando-os segundo critérios de "atualidade", "sociabilidade" e "imprevisibilidade". Projetando o debate para o campo jornalístico, seriam estes os valores-notícia que regem a lógica de tematização do mundo.

Por fim, seguindo a perspectiva de Patrick Charaudeau (2003), a dinâmica de constituição do espaço público e seu consequente diálogo com a concepção de construção do acontecimento midiático (noticiabilidade) permite uma reflexão pertinente de ordem qualitativa: 1) se a seleção dos acontecimentos fenomêmicos e sua transformação em acontecimentos midiáticos está ligada à noção de espaço público; 2) e se a noção de espaço público, por definição, não é universal, mas depende das especificidades culturais dos grupos sociais (o espaço público é "plural e móvel”); 3) logo, a seleção de acontecimentos midiáticos não pode ser encarada de maneira enrijecida por estar intimamente relacionada aos padrões culturais de cada grupo. Refina-se esta conclusão com os compromissos teóricos de Patrick Charaudeau apresentados inicialmente: as articulações entre os planos situacional e linguístico e entre os planos macro e microssocial.

\section{Considerações finais}

Por que as notícias são como são? O questionamento seminal deste trabalho permanece latente nos estudos teóricos que se preocupam com o "fazer jornalístico". Procurou-se, neste sentido, fornecer uma contribuição ao debate por meio das contribuições discursivas, adicionando novos elementos na complexa grade conceitual para o entendimento da lógica dos valores-notícia no jornalismo. Este caminho, é evidente, ainda está por ser pavimentado (e complementado com novas perspectivas), mas a contribuição do presente trabalho já se coloca como espécie luz para a discussão. Desta forma, as reflexões aqui estabelecidas firmam-se como um ponto de partida para análises empíricas a respeito do emprego dos valores-notícia na prática jornalística.

Alguns pontos merecem ser sublinhados. Em primeiro lugar, a perspectiva de cunho não-determinista localizada na obra de Patrick Charaudeau. Por conseguinte e finalmente, ressalta-se que o entendimento da concepção de noticiabilidade a partir das contribuições do autor francês significa, em última instância, valorizar os lugares de pertinência do contrato comunicacional, a lógica dos processos de transformação e transação na problemática da construção do sentido e a relação entre estruturação dos acontecimentos noticiosos e a tematização do espaço público, bem como - e sobretudo - a articulação entre os aspectos situacionais (externos) e linguísticos (internos) que se mobilizam na estruturação do discurso informativo. 


\section{Referências bibliográficas}

CHARAUDEAU, Patrick. El discurso de la información: la construcción del espejo social. Barcelona: Gedisa Editorial, 2003.

GALTUNG, Johan, RUGE, Mari Holmboe. A estrutura do noticiário estrangeiro - A apresentação das crises do Congo, Cuba e Chipre em quatro jornais estrangeiros. In: TRAQUINA, Nelson (Org.). Jornalismo: questões, teorias e estórias. 2.ed. Lisboa: Veja, 1999.

NOGUEIRA, Cláudio Marques Martins. Considerações sobre o modelo de análise do discurso de Patrick Charaudeau. In: Revista Ensaio. V.6. N.1. UFMG, julho 2004.

SOUSA, Jorge Pedro. Teorias da notícia e do jornalismo. Chapecó/Florianópolis: Argos/Letras Contemporâneas, 2002.

SOUSA, Jorge Pedro. Tobias Peucer: Progenitor da Teoria do Jornalismo. In: Revista Estudos em Jornalismo e Mídia. UFSC, v.1, n.2, 2004.

TRAQUINA, Nelson. Teorias do jornalismo: a tribo jornalística / uma comunidade interpretativa internacional. 2.ed. Florianópolis: Insular, 2008. 